\title{
IN VIVO DOCUMENTATION OF CELLULAR REACTIONS ON LENS SURFACES FOR ASSESSING THE BIOCOMPATIBILITY OF DIFFERENT INTRAOCULAR IMPLANTS
}

\author{
M. AMON and R. MENAPACE \\ Vienna, Austria
}

\begin{abstract}
SUMMARY
This prospective study was undertaken to assess the biocompatibility of different intraocular implants and to determine factors influencing cellular reactions on intraocular lenses (IOLs). Cellular reactions seen on the surface of 653 IOLs have been documented by specular microscopy. Various types of IOLs were used with different surgical procedures in humans. The 11 lens types used fall into five groups of materials: polymethylmethacrylate (PMMA), heparin surface-modified PMMA, surfacemodified PMMA, poly Hema and silicone. Factors influencing the cellular reaction on intraocular implants were elaborated on in this study. Besides the foreign-body reaction itself, cellular reactions were influenced by an increased inflammatory disposition, surgical trauma, peri-operative treatment, implant positioning and lens style. A significant correlation was found between the development of posterior synechiae and the existence of giant cells on the anterior lens surface. The incidence of cellular reactions on IOLs revealed significant differences specific to lens and material. Hydrophilic surfaces show cellular reactions in a lower percentage of cases compared with hydrophobic surfaces. An accurate and individual selection of lens material and style is mandatory to guarantee optimal results after surgery.
\end{abstract}

With the introduction of different intraocular lens (IOL) materials, styles and surface modifications it has become mandatory to test the biological interaction between the eye and the intraocular implant. In vitro and in vivo studies have shown that the cellular proliferation on the IOL surface is a good indicator of the biocompatibility of the lens material and of post-operative inflammatory reactions. ${ }^{1-6}$ This cellular reaction and its many influencing factors have also been reported. ${ }^{7,8}$

Correspondence to: Univ. Doz. Dr Michael Amon, First University Eye Clinic Vienna, Wöehringer Gürtel 18-20, A-1090 Vienna, Austria.
Specular microscopy allows the in vivo examination of cells on the IOL surface..$^{9-11}$ With this technique, various types of cells can be observed on IOLs at different times after implantation. The first cells to appear are small round cells that become spindle shaped (spindle-shaped cells) to perform active amoeboid movements and phagocytosis. $^{4,12-14}$ Later, epithelioid-like cells and giant cells develop..$^{4,9,15-17}$ All these cells are important in assessing the biocompatibility of IOL materials. The number of these cells depends on the IOL material, the degree of post-operative inflammation and the anatomical position of the IOL in the eye. ${ }^{7,15}$ These cells, which are derived from blood monocytes, ${ }^{18}$ are not the only ones seen on the IOL surface; however, the other cells do not have a great influence on the patient's immune response to the IOL materials. $^{4}$

Specular microscopy was used to perform in vivo examinations of 653 implanted IOLs of differing materials, surface modifications and styles, beginning during the early post-operative period and continuing for a mean follow-up of 10 months. Factors influencing the cellular reaction on intraocular implants were identified and an attempt was made to find quantitative and qualitative differences in the cellular reaction on the different IOL materials and styles, respectively.

\section{MATERIALS AND METHODS}

In this prospective study, cellular reactions on $653 \mathrm{IOL}$ surfaces have been documented using specular microscopy after implantation of various lens types in humans. Table I shows the different lens types used, sex and mean age of the patients, and the mean follow-up time for the different groups.

For cataract surgery a standardised technique starting with a scleral tunnel incision was used. After continuous circular capsulorhexis and hydrodissection of the lens,

Eye (1994) 8, 649-656 C 1994 Royal College of Ophthalmologists 
Table I. Patient data

\begin{tabular}{lcrr}
\hline Lens type & $\begin{array}{c}\text { Age } \\
\text { (years) }\end{array}$ & $n$ & \multicolumn{1}{c}{$\begin{array}{c}\text { Follow-up } \\
\text { (months) }\end{array}$} \\
\hline PMMA & & & \\
7 mm PMMA & $73 \pm 13$ & 84 & $8.3 \pm 2.9$ \\
7 mm HSM-PMMA & $72 \pm 13$ & 50 & $16.0 \pm 4.0$ \\
5 mm PMMA & $76 \pm 6$ & 67 & $8.2 \pm 3.4$ \\
5 mm SM-PMMA & $78 \pm 11$ & 50 & $5.8 \pm 1.5$ \\
Sulcus-fixated PMMA & $66 \pm 18$ & 15 & $5.3 \pm 2.1$ \\
Hydrogel & & & \\
Poly Hema 1103 & 75 & 200 & 6.0 \\
Poly Hema G triple & $77 \pm 5$ & 50 & $13.8 \pm 6.6$ \\
Poly Hema 1003 & $79 \pm 7$ & 34 & $9.2 \pm 2.9$ \\
Silicone & & & \\
Silicone disc & $76 \pm 7$ & 37 & $15.0 \pm 6.0$ \\
Silicone phacoflex & $76 \pm 9$ & 60 & $7.3 \pm 3.4$ \\
Total & 75 & 653 & 9.5 \\
\hline
\end{tabular}

HSM, heparin surface-modified; SM, surface-modified; G triple $=$ glaucoma triple procedure .

phacoemulsification was performed in all cases. Care was taken to place the IOL into the capsular bag. IOLs made of flexible materials (poly Hema and silicone) were folded for implantation using a Faulkner folder. Healon (Pharmacia) was the only viscoelastic material used throughout and the irrigation fluid was also the same in all procedures. In about $40 \%$ of patients a self-sealing incision was prepared; the others received radial 10/0 nylon sutures.

In addition to standard cataract surgery, combined cataract-glaucoma procedures were performed in 50 cases (group: poly Hema glaucoma triple). In this group, phacoemulsification and implantation of a folded 1103 poly Hema IOL were combined with trabeculectomy. ${ }^{19}$

In aphakic eyes, sulcus-fixated implants were used (group: sulcus-fixated PMMA). This heterogeneous group consisted of severely injured aphakic eyes and it was necessary to combine complex surgical procedures (vitrectomy, perforating keratoplasty, pupilloplasty, etc.) with the implantation of a sulcus-fixated implant. The exact pathological history and detailed surgical techniques used in this group have been published previously. ${ }^{20}$

The lenses used were made of polymethylmethacrylate (PMMA), heparin surface-modified (HSM) PMMA, surface-modified (SM) PMMA, poly Hema or silicone. Lens types and surface characteristics are listed in Table II. On HSM-PMMA IOLs the heparin molecule is covalently bonded to polyethylenimine, which is electrostatically bonded to PMMA. The surface of SM-PMMA IOLs is molecularly smoothed during the manufacturing process to prevent both protein and cell adhesion. The IOL is made oleophobic, although nothing is added or bonded to the PMMA surface.

In uneventful cases post-operative treatment was standardised and consisted of four times betamethasone and four times indomethacin eyedrops for 4-6 weeks. In patients with increased post-operative inflammation, treatment was adjusted to the individual situation.

For photographic documentation of morphological and cytological findings, a Zeiss non-contact specular micro- scope was used in all cases. The pupil was dilated and areas of interest on the IOL surface and the anatomical position were examined by specular microscopy. A semiquantitative method was chosen to estimate the density of small round cells and spindle-shaped cells on the lens, ${ }^{7}$ using the scale: + , fewer than 50 cells $/ \mathrm{mm}^{2} ;++$, fewer than 100 cells $/ \mathrm{mm}^{2} ;+++$, more than 100 cells $/ \mathrm{mm}^{2}$. This method was compared with a fixed-frame technique, the results being comparable. The exact technique for specular microscopy has already been described in detail. ${ }^{21,22}$

Observation times were the first 3 days, 7 days, 1 month and 6 months post-operatively. A final examination was performed 10 months after surgery. Besides the photodocumentation, accurate drawings with accompanying remarks were made.

For statistical analysis, the Fisher's exact test and the chi-quadrat test were used. A probability value of $p<0.05$ was taken to be significant.

\section{RESULTS}

During the first post-operative days small round cells and spindle-shaped cells were found on all implants (Fig. 1). Where there was increased post-operative inflammation, cell density was higher (Fig. 2). No significant difference was found pertaining to the different implant materials. Table III shows the cell density 7 days after surgery.

After several days, epithelioid cells and foreign-body giant cells were documented in some cases (Figs. 3, 4). Table IV and Fig. 5 show the results at the final examination. The percentage of foreign-body giant cells varied according to the lens type. These cells were seen most frequently on the silicone disc IOLs. In roughly $27 \%$ of cases foreign-body giant cells were seen on 7 mm PMMA, sulcus-fixated and poly Hema 1103 lenses after glaucoma triple procedures. For the $5 \mathrm{~mm}$ SM-PMMA IOLs the incidence was $20 \%$. On $5 \mathrm{~mm}$ PMMA and on silicone Phacoflex IOLs cellular reactions were found in $14.9 \%$ and $16.7 \%$ of cases, respectively. The $7 \mathrm{~mm} \mathrm{HSM-PMMA}$ and poly Hema (1103 or 1003) IOLs had the lowest percentage of cellular reactions. In statistical analysis this difference was significant (chi-quadrant test: $p<0.0005$ ) and was caused by the high percentage of foreign-body reactions on $7 \mathrm{~mm}$ PMMA, poly Hema glaucoma triple and silicone disc IOLs and by the low percentage on $7 \mathrm{~mm}$ HSM-PMMA, poly Hema (1103) and poly Hema (1003) IOLs.

Table II. Lens types

\begin{tabular}{lll}
\hline Lens type & Material & Surface property \\
\hline Adatomed 75 ST & PMMA & Hydrophobic/oleophilic \\
Pharmacia 725 C & HSM-PMMA & Hydrophobic/oleophilic \\
Pharmacia 740 P & PMMA & Hydrophilic/oleophilic \\
Optical Radi. Corp. & PMMA & Hydrophobic/oleophilic \\
$410 \mathrm{~F}$ & & \\
Polytech Poly 5 & PMMA & Hydrophobic/oleophilic \\
Ioptex Smart & SM-PMMA & Hydrophobic/oleophilic \\
Polytech PC 279 W & PMMA & Hydrophobic/oleophilic \\
Alcon logel 1103 & Poly Hema & Hydrophobic/oleophilic \\
Alcon logel 1003 & Poly Hema & Hydrophobic/oleophilic \\
Adatomed 90 D & Silicone & Hydrophobic/oleophilic \\
Allergan SI 26 NB & Silicone & Hydrophobic/oleophilic \\
\hline
\end{tabular}




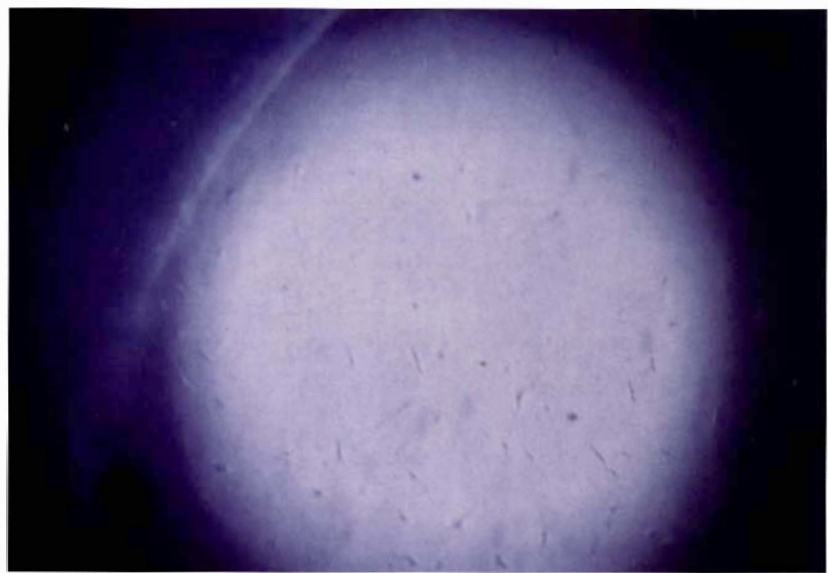

Fig. 1. Moderate number of spindle-shaped cells on a poly Hema 1103 IOL. Part of the capsulorhexis is visible. Cell density: $<50$ cells $/ \mathrm{mm}^{2}$. Original magnification $\times 130$.

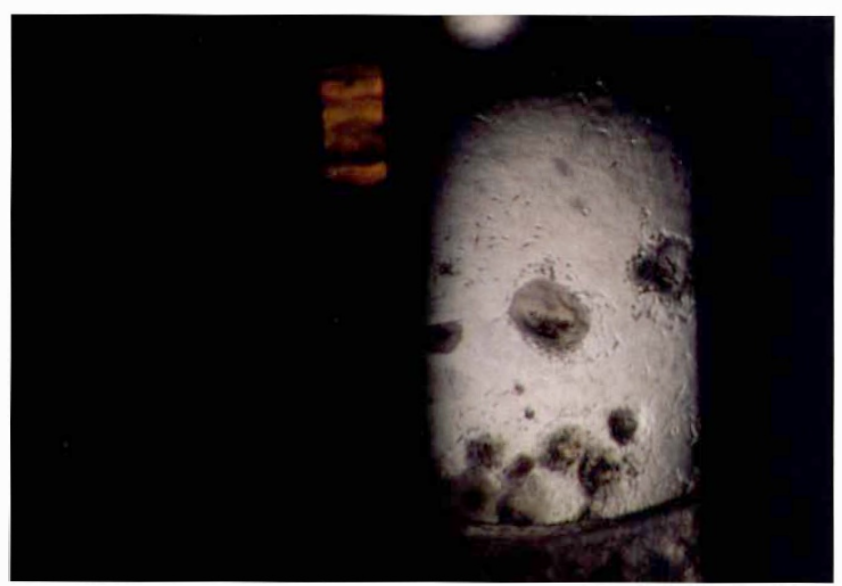

Fig. 3. Foreign-body giant cells with circular formation of spindle-shaped cells on a $7 \mathrm{~mm}$ PMMA IOL in a patient with chronic uveitis. Part of the capsulorhexis is visible. Original magnification $\times 40$.

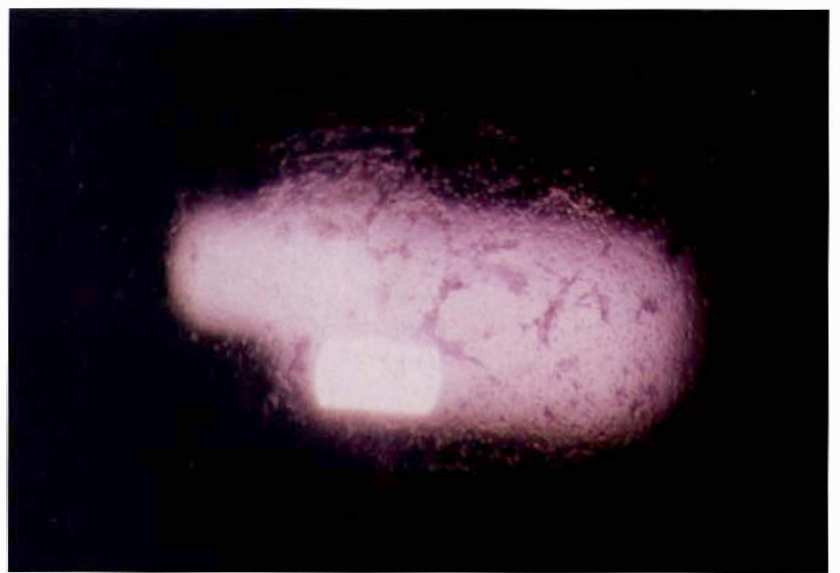

Fig. 2. High number of spindle-shaped cells and fibrinous strands on a $7 \mathrm{~mm}$ PMMA IOL in a patient with increased postoperative inflammation (diabetes mellitus). Cell density: $>100$ cells $/ \mathrm{mm}^{2}$. Original magnification $\times 40$

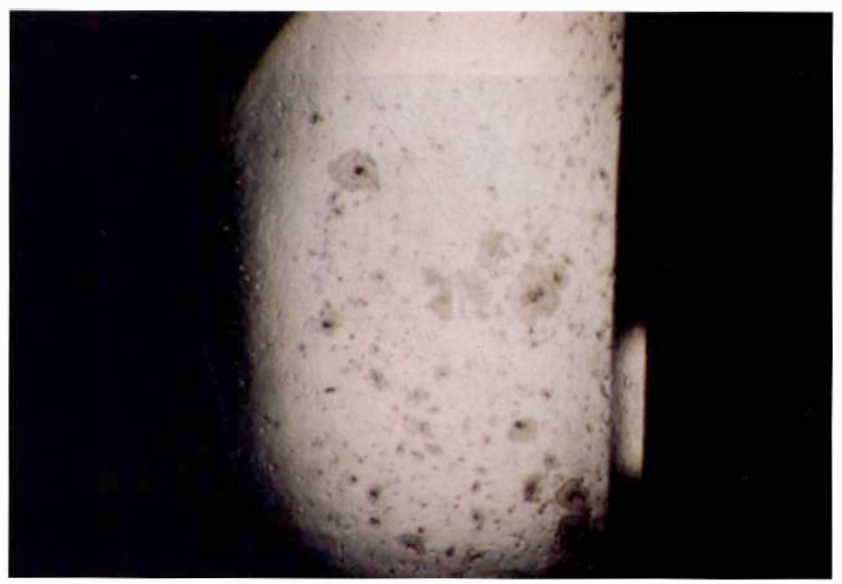

Fig. 4. Small round cells, spindle-shaped cells, epitheloid cells and foreign-body giant cells on a $5 \mathrm{~mm}$ PMMA IOL. Original magnification $\times 40$.

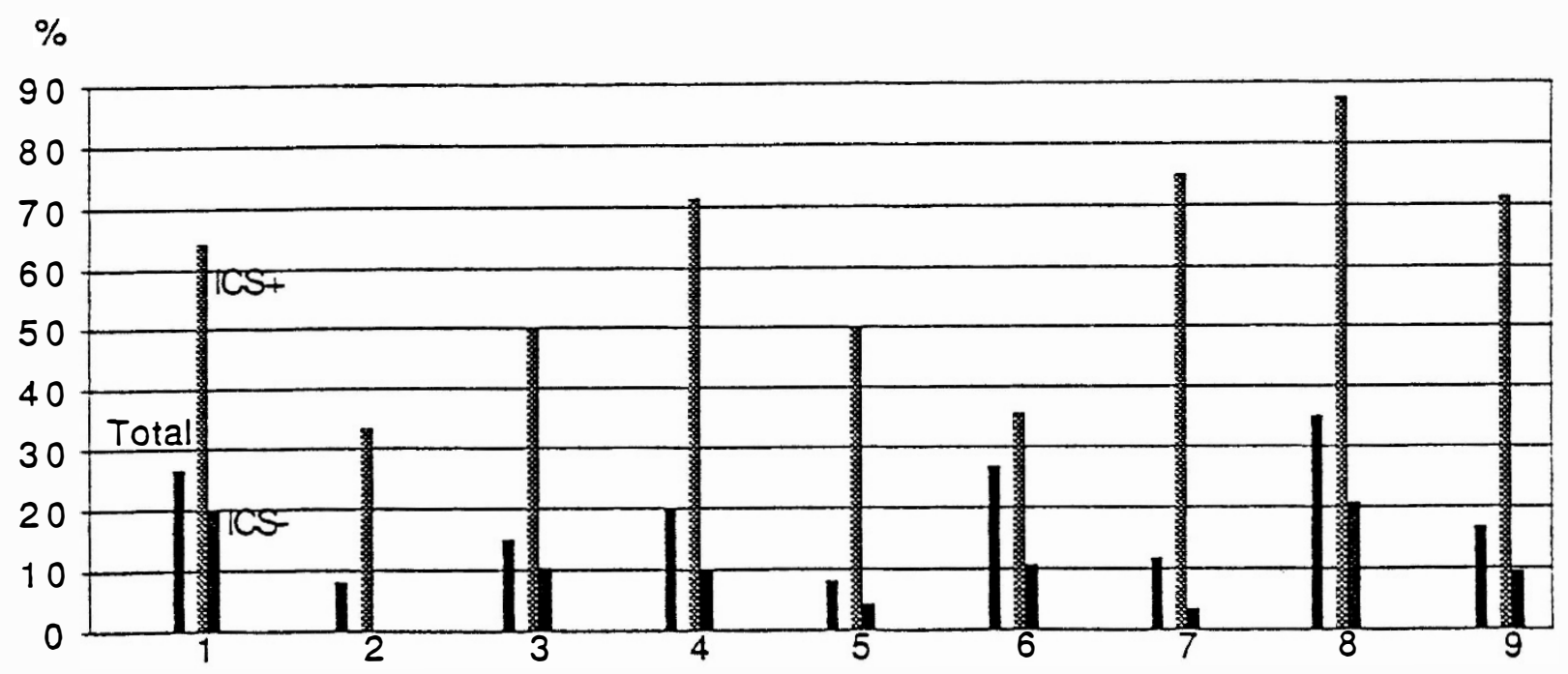

Fig. 5. Percentage of foreign-body giant cells on the different intraocular implants at the time of the examination following surgery: 1, 7 mm PMMA; 2, 7 mm HSM-PMMA; 3, 5 mm PMMA; 4, 5 mm SM-PMMA; 5, Poly Hema 1103; 6, Poly Hema glaucoma triple; 7 , Poly Hema 1003; 8, Silicone disc; 9, Silicone phacoflex. ICS+, all cases with iridocapsular/iridolenticular synechiae; ICS-, all cases without iridocapsular/iridolenticular synechiae. 
Table III. Cell density of small round cells and spindle-shaped cells on the different IOLs observed 7 days after surgery

Uneventful case Increased inflammation

\begin{tabular}{|c|c|c|}
\hline \multicolumn{3}{|l|}{ PMMA } \\
\hline 7 mm PMMA & $+/++$ & +++ \\
\hline 7 mm HSM-PMMA & $+/++$ & +++ \\
\hline $5 \mathrm{~mm}$ PMMA & $+/++$ & +++ \\
\hline $5 \mathrm{~mm}$ SM-PMMA & $+/++$ & +++ \\
\hline \multicolumn{3}{|l|}{ Hydrogel } \\
\hline Poly Hema 1103 & $+/++$ & +++ \\
\hline Poly Hema 1003 & $+/++$ & +++ \\
\hline \multicolumn{3}{|l|}{ Silicone } \\
\hline Silicone disc & $+/++$ & +++ \\
\hline Silicone Phacoflux & $+/++$ & +++ \\
\hline
\end{tabular}

+ , fewer than 50 cells $/ \mathrm{mm}^{2} ;++$, fewer than 100 cells $/ \mathrm{mm}^{2} ;+++$, more than 100 cells $/ \mathrm{mm}^{2}$.

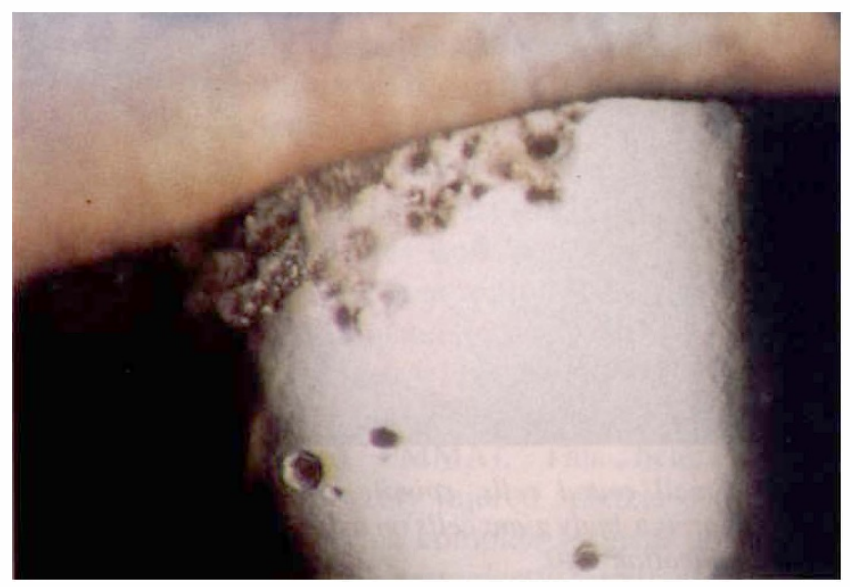

Fig. 6. Foreign-body giant cells on a 7 mm HSM-PMMA IOL. Iridocapsular synechia is visible at the area of cellular invasion. Original magnification $\times 40$.

It was demonstrated in all lens groups that those patients with iridocapsular or iridolenticular synechiae showed a significantly higher incidence of foreign-body giant cells than those without posterior synechiae (Fig. 6). The $7 \mathrm{~mm}$ PMMA, $5 \mathrm{~mm}$ SM-PMMA, poly Hema (1003), silicone disc, and silicone Phacoflex IOLs showed an occurrence rate of posterior synechiae and cellular reactions on the lens surface of over $64 \%$. The equivalent value was $50 \%$ for $5 \mathrm{~mm}$ PMMA and poly Hema (1103) IOLs, while $7 \mathrm{~mm}$ HSM-PMMA and poly Hema (1103) IOLs (glaucoma triple) showed a combined occurrence of less than 36\%. Sulcus-fixated PMMA implants were sutured at some distance from the iris, so that they did not show synechia formation and thus were excluded from this statistical calculation. On statistical analysis the difference between the groups was not significant (chiquadrant test: $p<0.11$, Fisher test: $p<0.11$ ).

As expected, in cases with no posterior synechiae, sul-
Table IV. Percentage of foreign-body giant cells and posterior synechiae on the different intraocular implants at the last visit

\begin{tabular}{|c|c|c|c|c|c|}
\hline & \multicolumn{5}{|c|}{ Foreign-body giant cells $(\%)$} \\
\hline & Total & $\begin{array}{l}\text { ICS/ } \\
\text { ILS+ }\end{array}$ & $\begin{array}{l}\text { ICS/ } \\
\text { ILS- }\end{array}$ & Select. & $\begin{array}{l}\text { ICS/ } \\
\text { ILS }\end{array}$ \\
\hline \multicolumn{6}{|l|}{ PMMA } \\
\hline $7 \mathrm{~mm}$ PMMA & 26.6 & 64.3 & 19.7 & 16.4 & 15.5 \\
\hline $7 \mathrm{~mm}$ HSM-PMMA & 8.0 & 33.3 & 0 & 0 & 24.0 \\
\hline 5 mm PMMA & 14.9 & 50.0 & 10.2 & 7.0 & 11.9 \\
\hline $5 \mathrm{~mm}$ SM-PMMA & 20.0 & 71.4 & 10.0 & 7.3 & 14.0 \\
\hline Sulcus-fixated PMMA & 26.7 & 0 & 26.7 & - & 0 \\
\hline \multicolumn{6}{|l|}{ Hydrogel } \\
\hline Poly Hema 1103 & 8.0 & 50.0 & 4.3 & 1.9 & 9.5 \\
\hline Poly Hema Gl triple & 26.9 & 35.5 & 10.5 & - & 62.0 \\
\hline Poly Hema 1003 & 11.7 & 75.0 & 3.3 & 0 & 11.8 \\
\hline \multicolumn{6}{|l|}{ Silicone } \\
\hline Silicone disc & 35.1 & 87.5 & 20.7 & 17.9 & 21.6 \\
\hline Silicone Phacoflux & 16.7 & 71.4 & 9.4 & 9.4 & 11.7 \\
\hline \multicolumn{6}{|l|}{ Statistical results: } \\
\hline Chi-quadrat test: $p<$ & 0.0005 & 0.11 & 0.0005 & 0.0005 & 0.0005 \\
\hline Fisher test: $p<$ & & 0.11 & & 0.00015 & \\
\hline
\end{tabular}

ICS/ILS+, all cases with iridocapsular/iridolenticular synechiae; ICS/ ILS-, all cases without iridocapsular/iridolenticular synechiae; Select., all cases without pre-existing factors influencing the inflammation after surgery and without ICS/ILS.

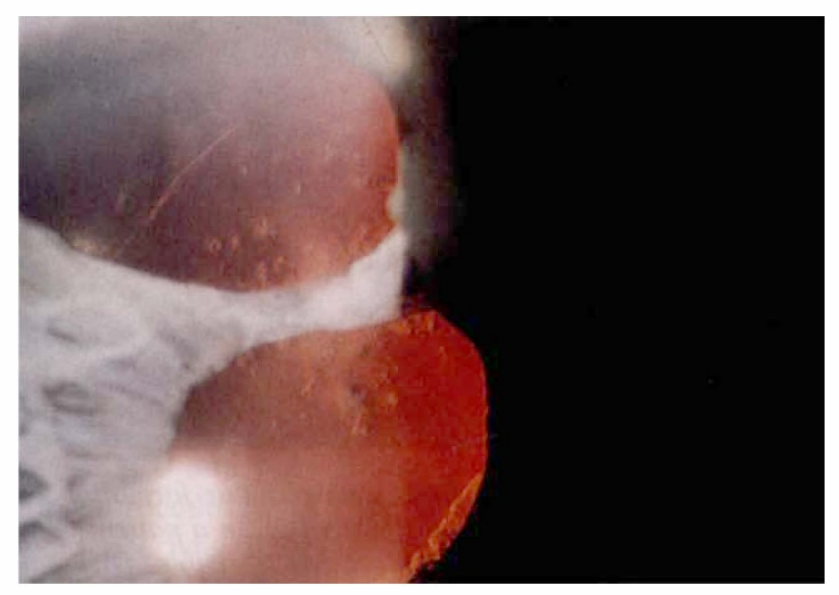

Fig. 7. Foreign-body giant cells on a poly Hema 1103 IOL in a glaucoma triple case. The cells migrate onto the IOL surface from both sides of the iridolenticular synechia. Original magnification $\times 16$.

cus-fixated PMMA implants showed the highest incidence of cellular reactions on the IOL surface, followed by the $7 \mathrm{~mm}$ PMMA and silicone disc IOLs (approx. 20\%).

In roughly $10 \%$ of cases foreign-body giant cells were documented on $5 \mathrm{~mm}$ PMMA, $5 \mathrm{~mm}$ SM-PMMA, poly Hema (1103) (glaucoma triple) and silicone Phacoflex IOLs. Poly Hema IOLs showed a very low percentage of these cells and the $7 \mathrm{~mm}$ HSM-PMMA IOLs exhibited no cells at the last examination. This difference was statistically significant (chi-quadrat Test: $p<0.0005$ ) and due to the high percentage of foreign-body reactions on $7 \mathrm{~mm}$ PMMA, sulcus-fixated PMMA and silicone disc IOLs and to the low percentage of such reactions on $7 \mathrm{~mm}$ HSMPMMA, poly Hema (1103) and poly Hema (1003) IOLs.

Excluding all patients with pre-existing factors influencing inflammation after surgery (diabetes mellitus, glaucoma, pseudoexfoliation syndrome, chronic uveitis, occlusion of the central vein, intumescent cataract, 


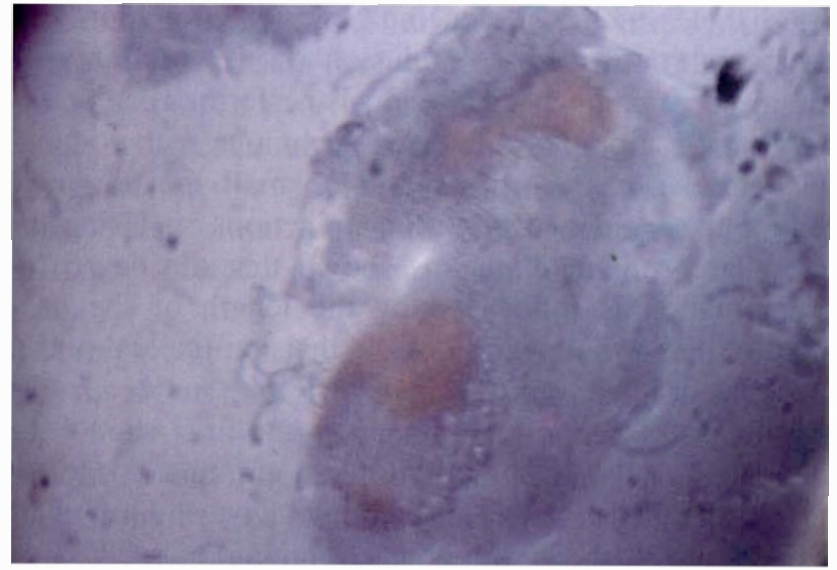

Fig. 8. Two large foreign-body giant cells $(>500 \mu \mathrm{m})$ with a high number of nuclei and vacuoles on a $7 \mathrm{~mm}$ PMMA IOL. Original magnification $\times 200$.

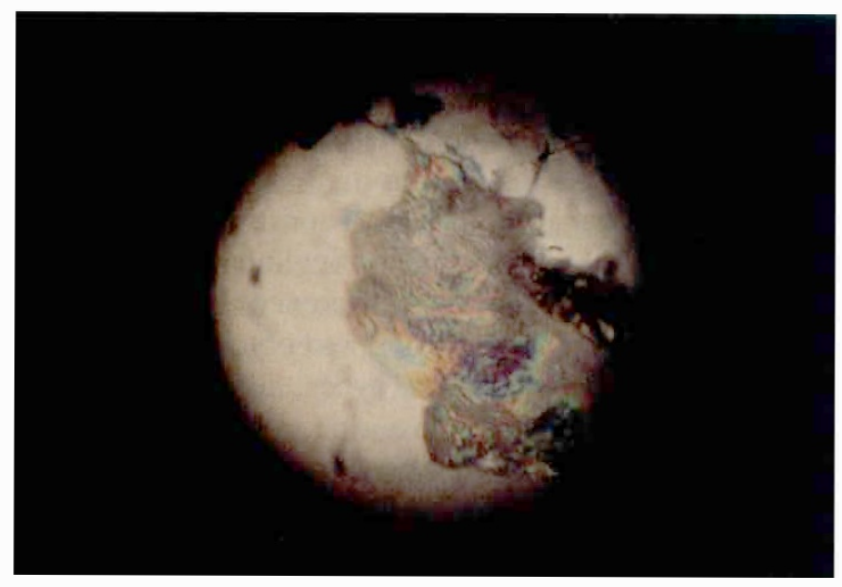

Fig. 10. Foreign-body giant cell with Newton's rings on a $7 \mathrm{~mm}$ PMMA IOL. Original magnification $\times 130$.

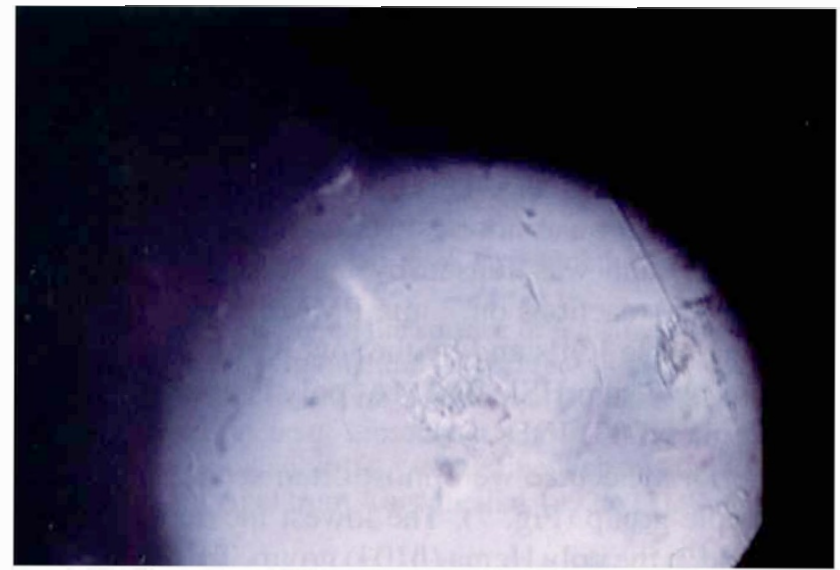

Fig. 9. Foreign-body giant cell with thin cytoplasm, vacuoles and nuclei on a $5 \mathrm{~mm}$ PMMA IOL. Original magnification $\times 130$.

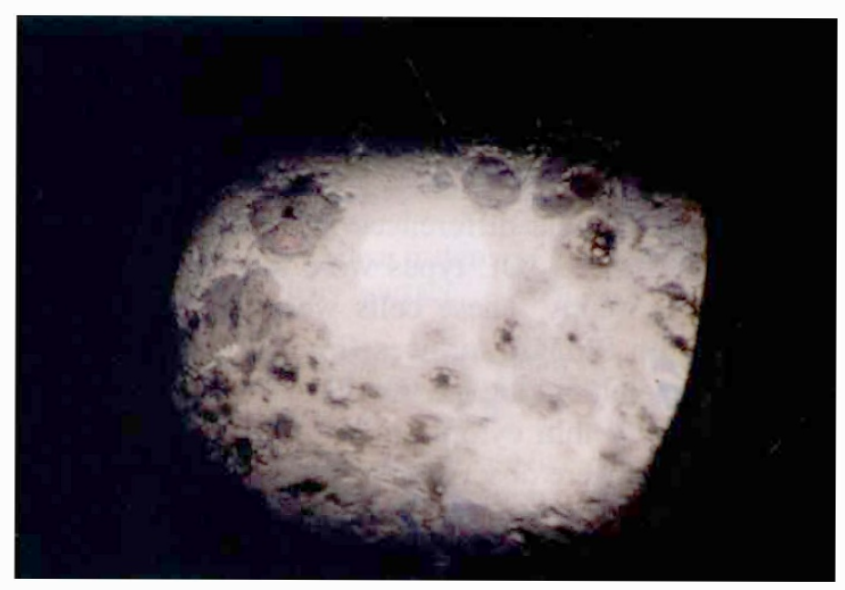

Fig. 11. Membrane-like formation of foreign-body giant cells on a $7 \mathrm{~mm}$ PMMA IOL in a case of chronic uveitis. Original magnification $\times 25$.

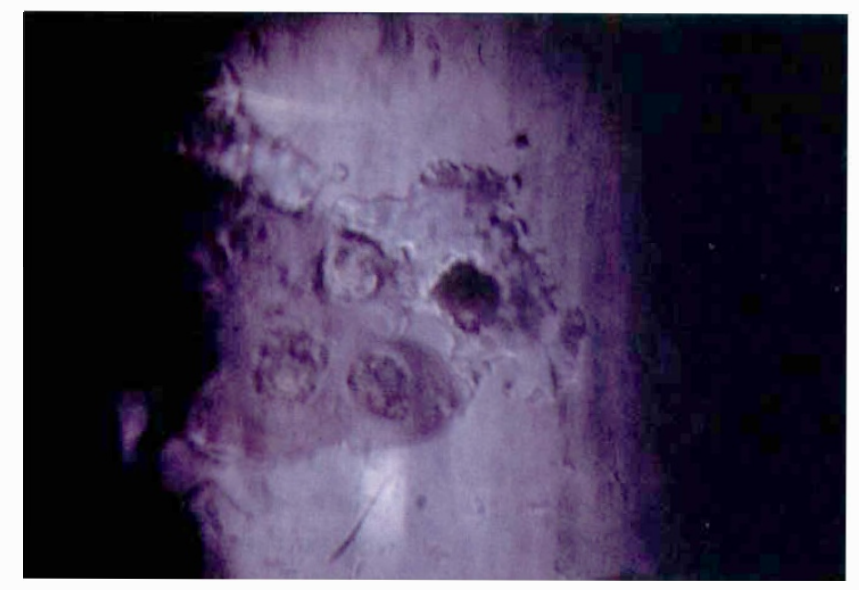

Fig. 12. Membrane of foreign-body giant cells. One cell exhibits an intracellular pigment granule. Original magnification $\times 130$. 
previously performed ocular surgery or radiation), the percentage of cellular reactions was somewhat lower than when only those cases with posterior synechiae were excluded. After this exclusion, no cells were detected on poly Hema ( 1003) IOLs. This difference was statistically significant (chi-quadrant test: $p<0.0005$, Fisher test: $p<0.00015$ ) and was caused by the high percentage of foreign-body reactions on $7 \mathrm{~mm}$ PMMA and poly Hema glaucoma triple IOLs and by the low percentage of such reactions on 7 mm HSM-PMMA, poly Hema (1103) and poly Hema (1003) IOLs.

Posterior synechiae were most often seen in the glaucoma triple group (Fig. 7). The lowest incidence (9.5\%) was found in the poly Hema (1103) group. This difference was statistically significant (chi-quadrat test: $p<0.0005$ ). The highest percentage of posterior synechia formation was found in the poly Hema glaucoma triple group, the lowest percentage in the poly Hema (1003) group.

In all groups, the percentage of cellular reactions was significantly higher in those cases exhibiting posterior synechiae (chi quadrant test: $p<0.05$ ).

Using specular microscopy to examine small round cells and spindle-shaped cells no significant morphological differences were found between the various lens groups.

The morphological differences in foreign-body giant cells on the various IOL types were also studied using specular microscopy. These cells were generally larger ( $>500 \mathrm{um}$ ) on PMMA surfaces (Fig. 8) than on HSMIOLs, poly Hema or silicone. On PMMA, the cells often exhibited a very thin cytoplasm with vacuoles (Fig. 9). Newton's rings were observed on some of all of the various lens types (Fig. 10), indicating a thin membrane on the IOL surface. These colourful fringes were created by the thin cellular cytoplasm or by acellular membranes, which cause interference of the reflected light. ${ }^{23}$

Membrane-like formations of foreign-body giant cells on the IOLs were sometimes documented on PMMA, poly Hema or silicone (Figs. 11, 12). In almost all cases these membranes were located close to the posterior synechiae. However, no morphological differences specific to the lens type or material were found when analysing membrane formation of foreign-body giant cells.

\section{DISCUSSION}

Factors influencing the cellular reaction on intraocular implants have been presented in previous studies ${ }^{7,8}$ and are further supported by this prospective study. There is a direct correlation between the degree of post-operative inflammation and the degree and percentage of cell reactions. ${ }^{1,3-9}$ In cases of increased post-operative inflammation, cell density of small round cells and spindle-shaped cells was higher in all groups.

In addition to the foreign-body reaction, cellular reactions are influenced by an increased inflammation disposition, trauma during surgery, peri-operative treatment, anatomical position of the implant and lens style. ${ }^{3,7.8}$ Preoperative factors influencing the cellular reaction on IOLs are diabetes mellitus, glaucoma, pseudoexfoliation syndrome, chronic uveitis, occlusion of the central vein, intumescent cataract and previously performed ocular surgery or radiation. ${ }^{7,824}$ A surgical technique with continuous circular capsulorhexis and a small incision may reduce the incidence of cellular reactions. ${ }^{7.25}$ Using the laser-flare cell meter it was shown that the degree of inflammation is influenced by the length of the incision. ${ }^{26.27}$ Even the location of the incision (scleral tunnel incision or clear cornea incision) may influence the results. Intra-operative trauma to the iris should be avoided. Lens style should allow an atraumatic implantation $^{3}$ and the lens surface should not have any irregularities. Here, chemical and physical properties of the lens surface play a major role..$^{28}$

The formation of posterior synechiae may be provoked by increased post-operative inflammation with and without fibrin, post-operative flattening of the anterior chamber, inadequate lens positioning and flaps of the anterior capsule when using a 'can-opener' capsulotomy.'

A significant correlation between the development of posterior synechiae and the existence of foreign-body giant cells on the anterior lens surface was found. In cases with iridocapsular or iridolenticular synechiae resident macrophages of the iris stroma may move onto the lens surface. ${ }^{12,5-17,29}$ Posterior synechiae constitute a risk factor with respect to the development of cellular reactions.

Quantitative and qualitative differences specific to lens and material were found. In order to obtain valid results when comparing different lens types, all cases with preexisting risk factors and posterior synechiae must be excluded. ${ }^{7}$ Only selected cases using the same surgical technique and the same peri-operative treatment should be used to reach conclusions on the biocompatibility of IOLs.

The percentage of foreign-body giant cells on the different lens types varied significantly. On PMMA lenses, cells were documented most frequently in cases with injured eyes receiving a sulcus-fixated implant. Due to the inflammatory disposition and the increased trauma during surgery, this result was expected. Another reason is an effect on the blood-aqueous barrier of the sutured haptic, as it is in constant contact with uveal tissue. ${ }^{30}$ On smalloptic PMMA IOLs cells were seen less often than on $7 \mathrm{~mm}$ optic PMMA IOLs. This could be explained by the fact that smaller incisions show less inflammation postoperatively. studies with the laser-flare cell meter have demonstrated this effect. ${ }^{26.27}$ No significant difference could be found between $5 \mathrm{~mm}$ PMMA and $5 \mathrm{~mm} \mathrm{SM-}$ PMMA IOLs. HSM implants had cells less frequently than the other PMMA IOLs. As shown in other studies on biocompatibility, a hydrophilic IOL surface seems preferable to hydrophobic or oleophobic surfaces $1,9,31$

Low percentages of foreign-body giant cells were found on the poly Hema IOLs, with both poly Hema lens styles showing similar results. This underlines the sensitivity of the evaluation technique. Cellular reactions were seen more often in glaucoma triple procedure cases with implantation of a poly Hema IOL than in those with stan- 
dard cataract surgery and implantation of the same lens type. After glaucoma triple procedures, the formation of posterior synechiae was significantly higher than after simple cataract procedures alone. The high incidence of synechiae in this group was caused by a glaucomainduced disposition, increased intra-operative trauma (iridectomy, scleral flap), and flattening of the anterior chamber. ${ }^{19}$

Foreign-body giant cells were found more often on silicone disc IOLs than on three-piece silicone IOLs. This can be attributed to the lens style and the resulting increase in traumatisation of ocular tissue during implantation. ${ }^{3}$

Hydrophilic lens surfaces showed a lower frequency of foreign-body giant cells than hydrophobic lens surfaces. We therefore believe that hydrophilic IOL surfaces suggest a higher biocompatibility. Chemical and physical properties of the lens surface play a major role in influencing the foreign-body reaction.

Pigment deposits were found more frequently on hydrophobic surfaces. ${ }^{9}$ This may be explained by the reduced invasion of cells resulting in reduced phagocytosis of the pigment by macrophages. ${ }^{9}$

Morphological differences in the foreign-body giant cells on the various lens types were also documented. On PMMA, cells were usually flatter and larger than on HSMand SM-PMMA, poly Hema or silicone surfaces. Newton's rings were created by a cellular lamella or an acellular proteinaceous membrane. Newton's rings develop because of the interference of light reflected from interfaces of materials with different refractive indices. ${ }^{23}$ This phenomenon was observed on all lens types.

Experimental studies have shown that a dense membrane of foreign-body giant cells may reduce visual acuity. ${ }^{32.33}$ If the cellular membrane cannot be reduced by conservative antiphlogistic treatment, YAG laser abrasion is a low-risk therapeutic alternative. ${ }^{33}$ Evidence of reduced contrast sensitivity and glare disability resulting from moderate cellular invasion could not be found. ${ }^{34}$

The clinical results of the different lens types were comparable to those found in previous studies.

In vivo studies of cellular reactions on lens surfaces allow important conclusions concerning the pathophysiology after lens implantation. Strict guidelines are necessary to obtain valid results. The in vivo documentation of cellular reactions is an important method of assessing the biocompatibility of different intraocular implants with high sensitivity and high specificity.

Key words: Biocompatibility, Foreign-body giant cells, Intraocular lenses, Polymethylmethacrylate (PMMA), Silicone, Specular microscopy.

\section{REFERENCES}

1. Amon M, Menapace R. Cellular invasion on hydrogel and PMMA lens implants: an in vivo study. J Cataract Refract Surg 1991;17:774-9.

2. Amon M, Menapace R. Long-term results and biocompatibility of heparin surface-modified intraocular lens implants. J Cataract Refract Surg, 1993;19:258-62.

3. Amon M, Menapace R, Skorpik C. Cellular reaction on the surface of silicone-disc posterior chamber lenses implanted in-the-bag. Eur J Cataract Refract Surg, 1993;5:138-41.

4. Wenzel M, Reim M, Heinze M, Böcking A. Cellular invasion on the surface of intraocular lenses: in vivo cytological observations following lens implantation. Graefes Arch Clin Exp Ophthalmol 1988;226:449-54.

5. Wolter JR. Foreign body giant cells on intraocular lens implants. Graefes Arch Clin Exp Ophthalmol 1982;219: 103-11.

6. Wolter JR. Cell life on the surface of lens implants. Graefes Arch Clin Exp Ophthalmol 1982;218:244-9.

7. Amon M. Die Relevanz der in vivo Dokumentation zellulärer Reaktionen auf Linsenoberflächen für die Beurteilung der Biokompatibilität unterschiedlicher intraokularer Implantate. Spektrum Augenheilkd 1992;6 (3), Supplement 7.

8. Rossa V, Sundmacher R, Willers R. Risikofaktoren für eine fibrinöse Reaktion nach Hinterkammerlinsen-Implantation: eine retrospektive Studie. Klin Monatsbl Augenheilkd 1992;2/200: 101-4.

9. Amon M, Menapace R. In vivo observation of surface precipitates of 200 consecutive Hydrogel-IOLs. Ophthalmologica 1992;201:13-8.

10. Ohara K. Biomicroscopy of surface deposits resembling foreign-body giant cells on implanted intraocular lenses. Am J Ophthalmol 1985;99:304-11.

11. Wenzel M, Reim M. Zellen auf intraokularen Linsen. Klin Monatsbl Augenheilkd 1987;191:279-82.

12. Uenoyama K, Tamura M, Kinoshita C, Kanagawa R, Ohmi S, Nakao T, Saika S. Experimental intraocular lens implantation in the rabbit eye and in the mouse peritoneal space. V. Phagocytosis and nuclear patterns of giant cells observed on the implanted lens surface. J Cataract Refract Surg 1990;16:465-70.

13. Wenzel M, Machata G. Zellbewegungen auf intraokularen Linsen. In: Jacobi KW, editor. 1. Kongress der DGII. Berlin: Springer, 1988:25-31.

14. Wolter JR, Lichter PR. Fibroblast-like cells on intraocular lens implants: phagocytosing erythrocytes. Br J Ophthalmol 1983;67:641-5.

15. Uenoyama K, Kanagawa R, Tamura M, Matoba $M$, Enomoto Y, Ohmi S. Experimental intraocular lens implantation in the rabbit eye and in the mouse peritoneal space. I. Cellular components observed on the implanted lens surface. J Cataract Refract Surg 1988;14:187-91.

16. Uenoyama K, Kanagawa $R$, Tamura $M$, Matoba $M$, Enomoto Y, Ohmi S. Experimental intraocular lens implantation in the rabbit eye and in the mouse peritoneal space. II. Morphological stages of the macrophage on the implanted lens surface. J Cataract Refract Surg 1988;14:192-6.

17. Uenoyama $K$, Kanagawa $R$, Tamura $M$, Matoba $M$, Enomoto Y, Ohmi S. Experimental intraocular lens implantation in the rabbit eye and in the mouse peritoneal space. III. Giant cell formation on the implanted lens surface. J Cataract Refract Surg 1988;14:197-201.

18. Allgöwer M, Hulliger L. Origin of fibroblasts from mononuclear blood cells: a study on in vitro formation of the collagen precursor, hydroxyproline, in buffy coat cultures. Surgery 1960;47:603-10.

19. Menapace R, Skorpik C, Amon M, Radax U. Technik und Ergebnisse der Kleinschnitt-Kataraktchirugie bei gleichzeitiger Trabekulektomie oder Keratoplastik ('Modifizierte Triple-prozeduren'). Spektrum Augenheilkd 1990;4/5: 167-71.

20. Menapace R, Freyler H. Amon M, Radax U, Papapanos P. Techiken und Ergebnisse der transskleralen Nahtfixation von Hinterkammerlinsen im Sulkus ciliaris. Spektrum Augenheilkd 1992;6(1):20-30.

21. Wenzel M. Spiegelmikroskopische Befunde von Zellen auf Intraokularlinsen. In: sitzungsbericht der 148. Versamm- 
lung des Vereins Rheinisch-westfälischer Augenärzte 1986:257-67.

22. Wenzel M. Die quantitative zytologische Auswertung spiegelmikroskopischer Befunde von Linsenimplantaten. In: Kongress der Deutschen Gesellschaft für Intraokularlinsen Implantation. Berlin: Springer, 1990:67-73.

23. Hofmann HM. Ursachen entzündlicher intraokularer Reaktionen nach Linsenimplantationen. Augenärztliche Fortbildung 1990;13:152-61.

24. Okada K, Sagawa H. Newton rings on the surface of implanted intraocular lenses. Ophthalmic Surg 1989;20: 33-6.

25. Nishi O. Intercapsular cataract surgery with lens epithelial cell removal. II. Effect on prevention of fibrinous reaction. J Cataract Refract Surg 1989;15:301-3.

26. Gills JP, Sanders DR. Use of a small incision to control induced astigmatism and inflammation following cataract surgery. J Cataract Refract Surg 1991;17 Suppl:740-4.

27. Kaiya T. Observation of blood-aqueous barrier function after posterior chamber intraocular lens implantation. J Cataract Refract Surg 1990;16:320-4.
28. Brash JL, Lyman DL. In: Hair M, editor. The chemistry of biosurfaces. New York: Dekker, 1971.

29. Uenoyama K, Kanagawa R, Tamura M. Experimental intraocular lens implantation in the rabbit eye and in the mouse peritoneal space. IV. Cell adhesion, fibroblast-like cell, and lymphocytic cluster observed on the implanted lens surface. J Cataract Refract Surg 1989;15:559-66.

30. Miyake K, Asakura M, Kobayashi H. Effect of intraocular lens fixation on the blood-aqueous barrier. Am J Ophthalmol 1984;98:451-3.

31. Yalon M, Blumenthal M, Goldberg EP. Preliminary study of hydrophilic hydrogel intraocular lens implants in cats. Am Intraocular Implant Soc J 1984;10:315-7.

32. Wenzel M. Specular microscopy of intraocular lenses: atlas and textbook for slit lamp and specular microscopic examinations. Stuttgart: Thieme, 1993.

33. Amon M, Menapace R, Papapanos P, Radax U. YAG-Laser Abrasio von Fremdkörperriesenzellen auf Kunstlinsenoberflächen. Spektrum Augenheilkd 1992;6(1):32-6.

34. Vass C, Amon M, Menapace R. Einfluss der Zellbesiedelung von Intraokularlinsen auf die Konrast- und Blendungsempfindlichkeit. Spektrum Augenheilkd 1992;6 (5): 211-7. 